\title{
DEBATE
}

\section{A stronger policy of organ retrieval from cadaveric donors: some ethical considerations}

\section{L Hamer, M M Rivlin}

See end of article for

J Med Ethics 2003;29:196-200

authors' affiliations

......................

Correspondence to:

Dr M M Rivlin, Prospect

House, 32 Sovereign

Street, Leeds, LSI 4BJ, UK.

email michael@rivlin.co.uk

Taking organs from dead people seems, prima facie, to raise fewer ethical complications than taking organs from other sources. There are, however, serious ethical problems in taking organs from the dead unless there is premortem evidence that this is what the deceased would have wanted, or at least,

Revised version received 6 December 2002

Accepted for publication

12 January 2003 not have objected to. In this paper we will look at a "strong" opting out policy as proposed by John Harris. We will argue that people can be harmed after their death and that the posthumous removal of organs against their expressed wishes is one form that such harm might take. We also argue that Harris's claim that we show "equality of concern" between the donor and recipient requires too much.

$\mathrm{T}$ here is an increasing discrepancy between the number of organs available and the number of potential recipients. In the United Kingdom organ procurement from cadaveric donors currently operates on an "opt in" basis. The fact that there is a suitable ventilated body in an intensive care unit does not, legally or ethically, give us free rein to do as we like with it. Those who wish their organs to be used in the event of their death may choose to carry donor cards or to place their name on the organ donor register. If they should die in such a manner that their organs are suitable for transplant the subject of donation is raised with the relatives, who retain the power to override the donor's decision. In the case of someone who has not expressed an opinion during life the relatives are used as proxy decision makers. In the rare circumstance that the relatives cannot be traced and an appropriate search for them has been fruitless the "responsible officer" of the hospital in which the body lies may give consent. Under no other circumstances may cadaveric organs legally be removed.

Obviously, this system fails to capture all those dead people whose organs are potentially suitable for transplantation. Each year people who would make very suitable organ donors die in hospital without their organs being utilised. The precise number is very hard to estimate. Data is currently being collected on all hospital deaths in a three month period in 2002 in order both to gain an accurate knowledge of the number and to ascertain the reasons why suitable patients are not brought to the attention of the transplant teams. It is thought that perhaps as many as $25 \%$ of possible donors are not referred to transplant teams and their relatives are thus never approached regarding a donation. Furthermore, in the UK around $25-30 \%$ of families approached refuse consent for their relative's organs to be used. Thus there is a "pool" of recently deceased people whose organs are "wasted", whether due to pressures on intensive care staff preventing an approach being made, a very reasonable unwillingness to intrude on a family's grief, or a refusal by the next of kin.

In the last few years, considerable public and professional debate has addressed the question of whether the rules governing the decision to donate should be altered so as to provide more organs, given the huge potential benefit to those waiting for organs.

\section{A STRONG "OPTING OUT" PROPOSAL}

John Harris writes: "The donor card scheme is clearly failing us all. We must get away from the idea that people can allow their bodies and those of their relatives to be simply buried or burned when they die. This is a terrible and cruel waste of organs and tissue that may save life or restore health". ${ }^{1}$

Harris has a suggestion for rectifying this wastage: "There are ... two groups of people we must consider, donors and recipients. If we ask what each group stands to lose if their preferences are not respected we get very different answers. One group stands to lose their lives. The other group have already lost theirs and at worst, will know prior to death that one of the many things they want to happen after their deaths will not come to pass". ${ }^{1}$ So "[o]ne way of expressing an equality of concern for ... [the newly dead and their families and those in need of organs] ... bearing in mind what both stand to lose, would be to ensure, through legislation, that all cadaver organs, organs from dead bodies, should be automatically available at death without any consent being required. The dead after all have no further use for their organs, the living do".

It is unclear from Harris's public interviews whether he intends the scheme to include an opt out clause or not. On the one hand he says: "[p]eople would not have the ability to register objections except for the strongest reasons. They would have to explain why they would wish other people to die rather than have their organs used", ${ }^{2}$ on the other he draws an analogy with coroners' postmortem examinations, for which people may not refuse consent. It seems that, although Harris would prefer to include an opt out clause, he believes that organs may be excised even against the will of "donors" if sufficient numbers cannot be obtained by other means. He says: " $[t]$ he crunch, of course, comes when ... conscientious objection will cost lives. Then we have a hard choice to make. It is surely far from clear that people are entitled to conscientiously object to practices that will save innocent lives. ... Fully consensual schemes are always best. But when so much is at stake, thousands of lives in Britain alone, and hundreds of thousands, perhaps millions worldwide, we must consider even mandatory schemes to prevent such needless loss of life". ${ }^{\prime \prime}$

What, if anything, is wrong with this policy? We begin by noting that we agree with Professor Harris that the number of organs available for transplant should, obviously, be increased if the increase can be achieved by morally acceptable means. We depart from him when we consider what is morally acceptable: we think that his proposed policy is too 
demanding. We do not (necessarily) object to opt out policies-we do object to non-opt out policies.

It is clear that the problem with Harris's "equal consideration for the potential donor and the recipient" requirements is wider than the specific case of organ donation. It is, rather, a particular example of the ongoing debate in moral philosophy about the relative primacy of the right and the good. The response to Harris's claim, then, goes much deeper than this particular problem in applied ethics, and forms an objection to utilitarianism considered as a whole.

We oppose Harris's argument on two broad grounds: "the problem of distributive justice" and "non-moral space". Both objections stem, essentially, from the fact that utilitarianism denies freedom to moral agents: firstly because it requires that they be used as means to another's end if the consequences are sufficiently good, and secondly because they are compelled at all times to maximise good results. In opposition to this we might say, with Charles Fried: "right and wrong have an independent and overriding status because they establish our basic position as freely choosing entities. That is why nothing we choose can be more important than the ground-right and wrong-for our choosing. Right and wrong are the expressions of respect for persons-respect for others and self respect". ${ }^{3}$

\section{THE PROBLEM OF DISTRIBUTIVE JUSTICE}

The first problem is that while it is rational within a life to suffer harm in order to obtain some benefit, this principle cannot straightforwardly be applied between people in the manner that Harris attempts here. As Norman Daniels writes: "it is rational and prudent that I take from one stage of my life to give to another, in order to make my life as a whole better. But it is morally problematic just when society can take from one person to give to another in order to maximise, say, total happiness". ${ }^{4}$ John Rawls sets out the utilitarian position as follows: "a society is properly arranged when its institutions maximise the net balance of satisfaction. The principle of choice for an association of men is interpreted as an extension of the principle of choice for one man". ${ }^{5}$ Making this extension work requires "conflating all persons into one through the imaginative acts of the impartial sympathetic spectator" and so the fundamental objection is that " $[\mathrm{u}]$ tilitarianism does not take seriously the distinction between persons". ${ }^{6}$ We usually think that courses of action that involve harming innocent people (as well as others such as lying and stealing) are morally unavailable to us even if our goal is to help others: this thought is denied by the utilitarian.

We offer two applications of the thought that there are things we must not do to people, even with the intention of helping many others. The first is that the dead themselves are harmed by being used for organs against their wishes. As Harris notes, the dead have already lost their lives-they cannot ever again be aware of any harm done to them. He believes it follows from this that the worst thing that can happen to them is knowing premortem that their wishes will not be respected. We disagree: we wish to argue that the dead have "surviving interests" which are capable of being harmed and these interests provide moral reasons against their being used. We also briefly consider two variations on the idea that we have moral obligations to the dead that do not stem directly from properties of the dead people themselves.

\section{INTERESTS AND HARMS}

How can something happening after death be a harm to the dead person? This is a tricky problem as intuitions pull in both directions. On the one hand we do feel sorry for a dead person if a project to which they devoted their lives collapses in ruins soon after their death, on the other hand, we are acutely conscious of the fact that they can never know of it. In what follows we pursue the theory of interests and harming proposed by Joel Feinberg ${ }^{7}$ because it offers the best support for our belief that dead human beings have direct moral status-that we have moral obligations to them which stem from properties of the dead person themselves. ${ }^{8}$ For reasons of space here we offer only a sketch of the theory. Feinberg writes: "One's interests, then, taken as a miscellaneous collection, consist of all those things in which one has a stake, whereas one's interest in the singular, one's personal interest or self interest, consists in the harmonious advancement of all one's interests in the plural. These interests, or perhaps more accurately, the things these interests are in, are distinguishable components of a person's wellbeing". ' There is a commonsense link between consciousness (or sentience) ${ }^{10}$ and interests then: we feel that, usually, consciousness is necessary for the possession of interests. And interests are necessary for moral status-we can only have obligations to (rather than regarding) a thing if it is capable of caring what happens to it.

There is a problem with this sort of talk. It seems perfectly reasonable to talk of things being better or worse for some non-that is, never-sentient beings. For instance, it is better for my plant if I water it, worse if I forget to do so. Although, however, we agree it makes sense to talk of what is good or bad for non-sentient things, the "needs" of plants and artefacts are not the sort of needs that generate interests. Rather, when we use terms such as "needs" and "welfare" with regard to these kinds of things we are really referring to the effect that damage to these things has on creatures with interests. Steven Sapontzis states: "[w]hile 'need', 'want', 'lack', 'harm', 'benefit', and 'good' are all commonly applied to plants, artifacts, and so on, 'interest' is not. 'Interest' is commonly reserved for the people and animals who will benefit or be harmed by the needs of plants, artifacts and so on being unmet". ${ }^{.1}$

So we follow Feinberg in believing the "welfare" of nonsentient things to be "welfare" in only a derivative sense, one that does not confer interests-which does not entail the object itself caring. This is not to claim that what happens to non-sentient things does not matter at all. We simply wish to claim that it does not matter "to them".

How then can we ascribe interests to the dead? We are acutely conscious of the fact that they can never again know what befalls them. What makes them different from plants and artefacts?

\section{POSTHUMOUS HARMING: TWO PROBLEMS}

We will argue that posthumous events can harm the dead because they have surviving interests which are capable of being harmed. It matters to them when these interests are invaded by the actions of other.

In what follows we assume for the sake of convenience that death is the end of existence. There seem to be two separate problems with the idea that some interests can survive death. The first, usually called the "experience problem", is the problem we face in making sense of the idea that someone can suffer a harm and not be aware of it. The dead obviously cannot be aware of anything that happens after their death. To claim, however, that the dead cannot be harmed because they are unaware of the harm commits one to some rather unintuitive beliefs concerning those living people who are harmed yet are unaware that they have been harmed. The experience requirement for harming applies to persons still living who are betrayed, deceived, and ridiculed behind their back, even if their lack of awareness is due to something of rather less consequence than death-say perhaps they are on holiday on a remote island with no telecommunications. In the case of harm to a living but ignorant person, however, we do not usually think the harm is done only when it is discovered. If the act itself were not harmful then the discovery of it would not be a bad thing. Nagel says: “Loss, betrayal, deception, and ridicule are on this view bad because people suffer when they 
learn of them". He continues: "The natural view is that the discovery of betrayal makes us unhappy because it is bad to be betrayed-not that betrayal is bad because its discovery makes us unhappy". ${ }^{12}$

For example:

1. Assume that George has left Mary a large inheritance in his will. Jane, however, one of the other beneficiaries, has managed to fraudulently alter the will so that Mary receives nothing. Mary does not even know of the existence of George, let alone the will. Let us further assume that Mary will never find out about the will or the inheritance. It is obvious that Mary has been harmed although she is and always will be, unaware of the fact.

2. Sandra is having an investigation under a general anaesthetic. While she is unconscious a male doctor examines and lightly touches her genitalia for his own gratification. There will be no physical evidence of the abuse and Sandra will never find out it has occurred. It is none the less difficult to argue that she has not been harmed.

Difficulties in attributing interests to the dead extend, however, beyond the "experience problem". If someone expresses an objection during life to the removal of their organs after death for transplant purposes, once they are dead then not only is there no longer a person who holds these opinions or objections, but also the person is no longer capable of being distressed if the wishes are violated. Surely then, there is no longer a subject of such a harm. As long as one is alive one's posthumous wishes are not in a position to be damaged, once one dies there is no "you" remaining to be harmed. In Tom Stoppard's Rosencrantz and Guildenstern are Dead the protagonists debate the "no subject" problem.

Rosencrantz: We might as well be dead. Do you think death could possibly be a boat?

Guildenstern: No, no, no ... Death is ... not. Death isn't. You take my meaning. Death is the ultimate negative. Not-being. You can't not-be on a boat.

Rosencrantz: I've frequently not been on boats.

Guildenstern: No, no, no-what you've been is not on boats. $^{13}$

This dialogue neatly captures the Epicurean idea that "... death, the most terrifying of ills, is nothing to us, since so long as we exist death is not with us; but when death comes, then we do not exist. It does not then concern either the living or the dead, since for the former it is not, and the latter are no more.".$^{14}$

Clearly the now dead person cannot be harmed: all that remains of him is his material body. To avoid this problem we must think of the person not simply in terms of his present condition but from an objective and timeless perspective. Feinberg writes: "The view I would like to defend is that the interests harmed by events that occur at or after the moment a person's non-existence commences are interests of the living person who is no longer with us, not the interests of the decaying body he left behind". ${ }^{15}$

This helps us to begin to make sense of the idea of harms occurring after death.

"All interests are the interests of some person or other, and a person's surviving interests are simply the ones that we identify by naming him, the person whose interests they were. He is of course at this moment dead but that does not prevent us from referring now, in the present tense, to his interests, if they are still capable of being blocked or fulfilled, just as we refer to his outstanding debts or claims, as if they are still capable of being paid. The final tally book on a person's life is not closed until some time after his death." 16

The idea that posthumous events can institute harms has enormous intuitive plausibility: most people (even philosophers who hold that harms, generally, must be experienced to count as harms-for example, Peter Carruthers ${ }^{17}$ ) think that death is a harm. More than that, they think that death is often the worst harm imaginable. ${ }^{18}$ Yet the "no subject problem" applies to the idea that being deprived of these opportunities is a harm with as much force as it does to the claim that we can suffer posthumous harm. If one denies that the latter can be harmful one must also deny that the former can be. And consider our everyday thoughts about murder: we do usually think that this is a great harm. But if the murder is instantaneous and painless then, according to the no subject problem, where is the harm? Or rather, to whom? This seems very counterintuitive.

We hope the preceding discussion is sufficiently compelling to convince the reader that there is at least "something" in the idea that one can be harmed by events occurring after one's death (although, given the seemingly intractable debate on the matter, we are sure they do not provide a conclusive answer). Having established, we trust, the intuitive plausibility of the idea that a dead person can be harmed, we now ask in what way can they be harmed?

\section{HARMING THE ANTEMORTEM PERSON}

Pitcher $^{19}$ and Feinberg ${ }^{7}$ distinguish two categories of thinking about the deceased: the postmortem person and the antemortem person. The former would be a description of the dead person as they are now-dead matter; the latter a description of the person as they were while living. Pitcher writes: "no one would want to argue seriously that a postmortem person can be harmed after his death.... A serious question can arise only over the issue of whether or not an antemortem person can be harmed after his death." ${ }^{20}$ There is an obvious problem to be avoided in this sort of account: "If the interests are those of the living person who is no more, then the problem is to explain how his lot can be made better or worse, as it were retroactively". ${ }^{21}$ Feinberg and Pitcher are at pains to point out that this account does not imply that the harmful posthumous event causes the antemortem person harm. Rather "posthumous harms do not entail backward causation because they ... do not entail physical causation at all.... The occurrence of the harmful posthumous event ... makes it true that the antemortem person is harmed, and that occurrence is in a sense responsible for the antemortem harm." ${ }^{22}$ Problems remain of course-not all interests are of a sort that can plausibly be said to survive death, desires for enjoyment-for example, must die with a person. There are also problems in determining when an antemortem person begins to be harmed by a posthumous event. As Feinberg notes: "we would be well advised not to seek more precision in answer to such questions than the subject matter permits". ${ }^{23}$

To conclude this section, it is at least plausible to say that the dead are harmed by events occurring after their deaths. If so, the removal of organs against the wishes of the deceased seems to be a definite case of posthumous harms. How powerful an objection is this though? Even if we accept that the dead may be harmed, Harris's point remains: there are people whose lives we could save by using these organs: the losses they suffer in dying seem greater than the losses suffered by the unwilling posthumous "donor".

It is open to Professor Harris to concede that the dead have surviving interests of this sort, imposing moral restrictions upon our treatment of them, but to deny that this means that 
we cannot use them as donors against their will. Perhaps the interests of those who require organs to live trumps the surviving interests of the dead regarding the disposition of their bodies. As an analogy, many people think that animals have interests which confer moral status, yet still find it morally appropriate to kill them for important (and not so important) human purposes.

We do not know whether an interest in posthumous bodily integrity should trump an interest in continued life (as a minor objection, even assuming we agree with Harris that such a comparison of "harms" is necessary we are at a loss to think of a way to go about it, except in a very rough intuitive manner). Our argument against the moral permissibility of removing organs against premortem wishes does not, however, rely only on the surviving interests idea.

\section{FURTHER SUPPORT FOR AGENT CENTRED RESTRICTIONS}

One line of support for our cause against Harris comes from an unlikely quarter. Many philosophers oppose Feinberg's claim that dead people can be harmed yet wish to retain the idea that some ways of treating dead human beings are morally wrong. These arguments take several forms, what follows may not exhaust the possibilities: (1) that failing to respect the wishes of the dead damages an important social institution and so constitutes a harm to the living who will worry about their posthumous wishes, and (2) that failing to respect the wishes of the dead shows a failing of an important virtue in the living - the dead are, as it were, a practice ground for our moral behaviour. Both of these proposals have merit-we think they certainly ought to be weighed. We think, however, that they constitute additional reasons against disrespecting the wishes of a dead person, working in conjunction and taking second place to, the theory of posthumous harming. The idea that certain things done to a dead person damage them, the dead person, underlies certain commonsense intuitions which we are loath to relinquish: we wish to ascribe direct moral status to the dead.

We have, however, a second response to the objection that we put into Professor Harris's mouth above.

\section{"NON-MORAL SPACE"}

By requiring that our concern for those in need of organs leads us to remove organs from the dead against their wishes, Harris's theory is too demanding. Utilitarianism makes no distinction between causing an event and allowing it to happen when it was physically within our power to prevent it-we are as responsible for outcomes which we fail to prevent when it is in our power to do so as we are for events we straightforwardly cause. For this reason Harris thinks that not only may people donate their organs, but that the suitable dead are obliged to "donate" their organs. He says that those who refuse to allow their organs to be used "would have to explain why they would wish other people to die rather than have their organs used"2 and suggests it is "surely far from clear that people are entitled to conscientiously object to practices that will save innocent lives". ${ }^{1}$ What can we say in response to this?

\section{THE IMPORTANCE OF INTENTION}

The first thing to note is that, by talking of "wishing to let people die", Harris seems to be tacitly appealing to the utilitarian claim that there is no moral difference between active killing and allowing to die. In the Marxist conception of violence he makes this point explicit: "If we have a duty not to kill others, it would be strange indeed if the duty not to kill by positive actions was somehow stronger than the duty not to kill by negative actions". ${ }^{24}$ But to say that those who refuse to donate their organs "wish other people to die" seems to be a very strange thing to say. Heidi Malm ${ }^{25}$ argues that we can differentiate between something that we simply did not do and something we refrained from with the intent that a harm occur. Why does Harris think that killing should be equivalent to letting die in this case? We accept that, in those popular thought experiments in which a doctor, believing death to be in his patient's best interests, either acts so as to hasten death or refrains from acting to slow the process, if the underlying intention-that the patient's suffering ends-remains the same, then perhaps it is difficult to speak of a moral difference between acts and omissions. However, someone who refuses to donate their organs need not have the death of the thwarted recipient as their intention, indeed we would be shocked and disgusted if this were the case! They may well fervently wish that the recipient obtain an organ from another source, or that they miraculously recover from their illness. They may also not think in terms of thwarted recipients at all. All the person who refuses to donate aims at, it seems to us, is having their body remain whole after their death.

\section{DENYING AGENTS FREEDOM}

On Harris's account, people are as responsible for damage causing situations or processes that they could prevent but do not, as they are for harms that involve a positive action on their part. The only fact that counts is the consequences: something has occurred which reduces the total amount of good in the world and which must be rectified if at all possible. But if omitting to help is thought of in these general terms - that the fact that there is someone, somewhere, who could be helped-it seems impossibly restrictive, denying agents the opportunity ever to be saintly, or to engage in nonmoral activities. The problem here is that, under utilitarianism, it seems impossible to do more than one ought-acts are divided into two categories: either morally obligatory or morally prohibited. Commonsense morality customarily adds a third category, supererogatory acts, which although a very good thing to do, are not obligatory. We do not usually think we are obliged to do "absolutely anything" to save others, even when the cost to us is relatively trivial. Although most of us would probably find someone who did not stoop to pull a drowning child from a shallow pond to be morally lacking, we do not give all the blood we can give $(90 \%$ of the population of the UK apparently does not give at all), we do not give all our spare money to charity, we do not all place ourselves on the bone marrow donation register. And we do not think ourselves morally blameworthy if we spend some of our time idly watching television or going on holiday rather than working for the underprivileged.

Bernard Williams says: "[i]t is because consequentialism attaches value ultimately to states of affairs, and its concern is with what states of affairs the world contains, that it essentially involves the notion of negative responsibility: that if I am ever responsible for anything, then I must be just as much responsible for things that I allow or fail to prevent, as I am for things that I myself, in the more everyday restricted sense, bring about". ${ }^{26}$ Under such a scheme, agents are required to give up their personal plans and projects and, presumably, those obligations and rights which stem not from general duties one has to everyone but which arise specifically from personal situations-families, friendships, and so on, whenever doing so would increase the general good. This requirement in itself is not the problem for utilitarianismalmost every other moral theory could require great sacrifice under appropriate circumstances. The problem lies in the utilitarian insistence that each agent in all cases produce the best available outcome. In other words, there is a discrepancy between "the way in which concerns and commitments are naturally generated from a person's point of view quite independently of the weight of those concerns in an inpersonal ranking of overall states affairs, and the way in which utilitarianism requires the agent to treat the concerns generated from his point of view as altogether dependent for their 
moral significance on their weight in such a ranking". ${ }^{27}$ It is this which alienates the agent "from his actions and the source of his action in his own conviction and thereby ... undermine [s] his integrity". ${ }^{28}$

\section{THE ODDNESS OF THINKING THAT REDUCING SUFFERING IS ALWAYS THE MOST IMPORTANT THING FOR US TO DO}

Why does the fact that there is this unfortunate state of affairs-a person whose organs are failing-have any consequences for what we, as uninvolved parties, not doctors or nurses, have to do? David Schmidtz makes this point well in a thought experiment he calls "fast pain relief". This imagines that there is a button that, if pushed, will cause all sentient life to painlessly cease to exist. "You will, of course, minimise suffering in the process." ${ }^{\prime 29}$ Schmidtz says, correctly we feel, that this case "shows us that minimising suffering is not the only thing that matters. Nor is it always what matters most. Further, there are things-for example, all sentient life that ought not to be sacrificed merely to minimize suffering." ${ }^{30}$ Whether minimising suffering matters a little or a lot in the cosmic scheme of things need not be addressed because "suffering could matter quite a lot without it being true that we ought to spend quite a lot of our lives working to put an end to it". ${ }^{31}$

\section{AN ASIDE ABOUT "PREVENTION CASES"}

To say all these things does not, of course, mean that the appeal to consequences has no power; it would be absurd to say this. This is the intuition from which Harris's point derives its strength. Most people (non-utilitarian philosophers included) tend to favour something like Harris's rule for maximising the number of lives saved under certain circumstances, or, at least, not to rule it out. But to attempt to determine those situations in which the rule should apply is to enter tricky territory. Certainly we would agree with Harris that under some circumstances, when we have a duty of easy rescue, then we are morally obliged to help. We even think that in disaster situations we may sometimes save some people by harming others.

What separates out these sorts of cases from the case of people dying for lack of organs? It is not always terribly clear, but some plausible suggestions are: (1) because the situations are usually emergency or disaster situations; (2) because they are usually "one offs" - our actions will not set a precedent, and (3) they are also situations in which a decision has to be made (often because all will die if we do not allow some to). Everyday tragedies, such as the plight of those in end stage organ failure, are sadly neither extraordinary nor likely to end in the foreseeable future. Thus they are not ones in which we feel a decision need be made-we cannot morally retrieve organs against the donors' and families' wishes. As Anne Maclean says "[t]he situation ... [of people with failing organs] ... is not at all unusual, and it would not be perceived as one which requires a decision or choice" ${ }^{32}$

\section{CONCLUSION}

We have tried to show that the dead may be harmed by having their organs excised contrary to their premortem wishes and to argue that we need not go to the lengths Professor Harris suggests in obtaining organs. We do not dispute that there would be enormous benefit to patients by permitting such harms, and we are keen to point out that our argument applies only to those donors who refuse consent-not to all donors. We think, however, that the proposed practice of excising organs from those who refuse consent cannot be justified morally, despite the great benefits that may obtain. It must not be thought that we are alone in taking such a stance. Readers will no doubt recall the case of the organ donation that was accepted with racist conditions attached. When the case became public, both the British Medical Association and the government said that in future such donations would be unacceptable even if patients died as a result.

\section{ACKNOWLEDGEMENT}

The authors would like to thank the two anonymous reviewers and Ann Lloyd, technical editor, for their helpful comments on the paper.

Authors' affiliations

C L Hamer*, Renal Transplant Unit, Manchester Royal Infirmary, Manchester, UK

M M Rivlin, Nuffield Institute of Health, University of Leeds, Leeds, UK

*Also a doctoral student, School of Philosophy, University of Leeds, Leeds, UK

\section{REFERENCES AND NOTES}

1 www.midwalesonline.co.uk and follow links to summer news 13.htm (accessed 9 December 2002).

2 http://news.bbc.co.uk and follow the links to /281404.stm (accessed 9 December 2002).

3 Fried C. Right and wrong. Cambridge, Ma: Harvard University Press, 1978.

4 Daniels N. Just health care. Cambridge: Cambridge University Press, 1985.

5 Rawls J. A Theory of justice [rev ed]. Oxford: Oxford University Press, 1971.

6 See reference 5: 24

7 Feinberg J. The moral limits of the criminal law. Voll Harm to others. New York: Oxford University Press, 1984

8 Warren MA. Moral status: obligations to persons and other living things. Oxford: Clarendon Press, 1997. For an informative discussion of the concept of moral status.

9 See reference 7: 34 .

10 See reference 8: 55

11 Sapontzis SF. Morals, reason, and animals. Philadelphia: Temple University Press, 1987.

12 Nagel T. Mortal questions. Cambridge: Cambridge University Press, 1979.

13 Stoppard T. Rosencrantz and Guildenstern are dead. London: Faber, 1968.

14 Feldman F. Confrontations with the reaper: a philosophical study of the nature and value of death. Oxford: Oxford University Press, 1992.

15 See reference 7: 89

16 See reference 7: 83

17 Carruthers P. The Animals issue: moral theory in practice. Cambridge: Cambridge University Press, 1992.

18 To say that "death is a harm" is perhaps not quite right-it would be odd to say that someone who has been dead for two hundred years has been harmed more than someone who has been dead only one hundred years. But it also seems odd to say that it is "dying" which is the harm. For the process of dying, in itself, may involve less suffering than some non-fatal illnesses or injuries - surely we only object to it because it leads to death? We lack the space to thoroughly discuss this interesting problem here, but wish to note that we are attempting to capture the idea that the harm done by death or dying seems to stem from what it deprives us of-the loss of all future opportunities for satisfaction.

19 Pitcher G. The misfortunes of the dead. Am Philos Q 1984;21:183-8.

20 See reference 21: 184

21 See reference 7: 89

22 See reference 7: 91

23 See reference 7: 92

24 Harris J. The Marxist conception of violence. Philos Public Aff 1974; 3:192-220

25 Malm H. Killing, letting die, and simple conflicts. Philos Public Aff 1989; 18:238-58.

26 Williams B. In: Smart JJC, Williams B. Utilitarianism, for and against. London: Cambridge University Press, 1973.

27 Scheffler S. The rejection of consequentialism: a philosophical investigation of the considerations underlying rival moral conceptions. Oxford: Clarendon Press, 1982.

28 See reference 29: 9

29 Schmidtz $\mathbf{D}$. Islands in a sea of obligation: limits of the duty to rescue. Law Philos 2000;19:683-705.

30 See reference $31: 688$

31 See reference 31:689.

32 Maclean A. The elimination of morality: reflections on utilitarianism and bioethics. London: Routledge, 1993. 